\title{
A Review of Further Directions for Artificial Intelligence, Machine Learning, and Deep Learning in Smart Logistics
}

\author{
Manuel Woschank ${ }^{1, *(1)}$, Erwin Rauch ${ }^{2}$ (I) and Helmut Zsifkovits ${ }^{1}$ \\ 1 Chair of Industrial Logistics, Montanuniversitaet Leoben, 8700 Leoben, Austria; \\ helmut.zsifkovits@unileoben.ac.at \\ 2 Industrial Engineering and Automation (IEA), Faculty of Science and Technology, \\ Free University of Bozen-Bolzano, 39100 Bolzano, Italy; erwin.rauch@unibz.it \\ * Correspondence: manuel.woschank@unileoben.ac.at; Tel.: +43-3842-402-6023
}

Received: 31 March 2020; Accepted: 29 April 2020; Published: 6 May 2020

\begin{abstract}
Industry 4.0 concepts and technologies ensure the ongoing development of microand macro-economic entities by focusing on the principles of interconnectivity, digitalization, and automation. In this context, artificial intelligence is seen as one of the major enablers for Smart Logistics and Smart Production initiatives. This paper systematically analyzes the scientific literature on artificial intelligence, machine learning, and deep learning in the context of Smart Logistics management in industrial enterprises. Furthermore, based on the results of the systematic literature review, the authors present a conceptual framework, which provides fruitful implications based on recent research findings and insights to be used for directing and starting future research initiatives in the field of artificial intelligence (AI), machine learning (ML), and deep learning (DL) in Smart Logistics.
\end{abstract}

Keywords: industry 4.0; artificial intelligence; machine learning; deep learning; smart logistics; logistics 4.0

\section{Introduction}

The fourth industrial revolution (Industry 4.0) comprises a set of concepts and technologies that should be used to strengthen the competitiveness of industrial enterprises by referring to the concepts of interconnectivity, digitalization, and automation [1-4]. In this context, Smart Logistics aims at the successful implementation of intelligent and lean supply chains based on agile and cooperative networks and interlinked organizations. Furthermore, information exchange is established through the usage of modern information and communication technologies (ICT), data networks, actors and sensors, and automatic identification and material tracking technologies. Moreover, automated transport, transition, and storage systems, supported by autonomous transport vehicles, should enable a partial and/or complete self-control of systems [2,4-6].

Furthermore, Smart Logistics can be implemented by using the technological concepts of cyber-physical systems (CPS), the internet of things (IoT), respectively as the industrial internet of things (IIoT), and the physical internet (PI) [2]. Besides the implementation of the technological concepts, the application of artificial intelligence, machine learning, and deep learning concepts can be considered as one of the most important success factors within the process of the digital transformation [7].

In this context, artificial intelligence (AI) can be defined as the science and engineering of intelligent machines with a special focus on intelligent computer programs [8]. Machine learning 
(ML) is considered as an integral part of AI, which refers to the automated detection of meaningful patterns in datasets. ML tools aim to increase the efficiency of algorithms by ensuring the ability to learn and adapt based on big-data analytics [9]. Moreover, deep learning (DL), is defined as a sub-class of ML within the AI-technologies that explores many layers of non-linear information processing for supervised and/or unsupervised features extraction and transformation, and for pattern analyses and classification $[10,11]$.

In recent years, $\mathrm{AI}, \mathrm{ML}$, and DL have gained increasing relevance in a multitude of research fields such as engineering, medicine, economics, and business management as well as in marketing [12-15]. However, to the best of our knowledge, a holistic study on the usage of AI, ML, and DL in the context of Smart Logistics in industrial enterprises is currently missing in the scientific literature. Therefore, the authors conduct a systematic literature review on AI, ML, and DL technologies in the timeframe from 2014 to 2019. The identified studies can be used to provide an overview of research on these emerging topics that can be used as a starting point for further studies in the area of Smart Logistics later on.

This paper is structured as follows. Section 2 describes the selected research methodology and methods of this study as well as the detailed process steps of the systematic literature review. Section 3 presents a descriptive analysis and the content analysis of the identified studies. Section 4 introduces the conceptual framework of AI, ML, and DL approaches in the research area of Smart Logistics in industrial enterprises. Section 5 contains a discussion of the research findings. Section 6 summarizes the implications for both future research initiatives and practical applications, and the limitations of this research study. The final Section 7 briefly concludes by reflecting on the main contributions of this paper.

\section{Research Methodology and Methods}

In this paper, the authors conduct a systematic literature review (SLR) for the secondary-data-based evaluation of recent research studies regarding the application of AI, ML, and DL approaches in the research area of Smart Logistics in industrial enterprises.

By including the sequential identification, screening, clustering, and evaluation of research-relevant studies in research-related areas, the SLR approach was selected because of its systematic, method driven, and replicable approach [16-18]. Especially for the generation and assessment of new knowledge, the SLR process is considered as a valuable instrument that minimizes various judgment biases by systematically evaluating relevant findings from recent research studies [19-21].

In this context, research offers a multitude of guidelines for SLR, which should be used to ensure high quality in empirical research [16,22-24]. In this study, the authors focus on the SLR guidelines as suggested by Denyer et al. [23] and Hokka et al. [16], which generally can be divided into the following four steps:

- $\quad$ Step 1: Definition of the research objective(s);

- Step 2: Framing of the research subject (conceptual boundaries);

- Step 3: Data collection by using inclusion/exclusion criteria;

- Step 4: Validation of the research results.

\subsection{Research Objectives}

This paper aims to systematically evaluate possible future directions for AI, ML, and DL in Smart Logistics by analyzing the current knowledge and the state of the research regarding AI, ML, and DL-related topics with a special emphasis on recent developments in industrial research. In particular, the authors want to understand how this research topic evolved during the last years. Moreover, the evaluation results will be used for the identification of key activities for further research as well as practical applications. 


\subsection{Framing of the Research Subject}

This research focuses on the systematic evaluation of artificial intelligence, machine learning, and deep learning approaches for Smart Logistics in industrial enterprises. Therefore, the research subject, i.e., the conceptual boundaries, was defined based on the term "artificial intelligence" and the related terms "machine learning" and "deep learning" in the industrial environment.

\subsection{Data Collection by Using a Set of Inclusion and Exclusion Criteria}

The SLR further requires a definition of search criteria, databases, search terms, and publication period. In this study, the authors have used Scopus as the main source for the keyword search, because it was identified as the most relevant database for scientific publications in the areas of engineering and management science. An additional review of similar databases (Web of Science, Science Direct, and Emerald) did not lead to significant differences in the resulting research studies. Therefore, the authors have decided to use Scopus as the main database for the evaluation of secondary data in the course of this research study.

The following Figure 1 shows the structured research process $[16,23]$ and the pre-defined inclusion and exclusion criteria, which are based on our overall meta-search query.

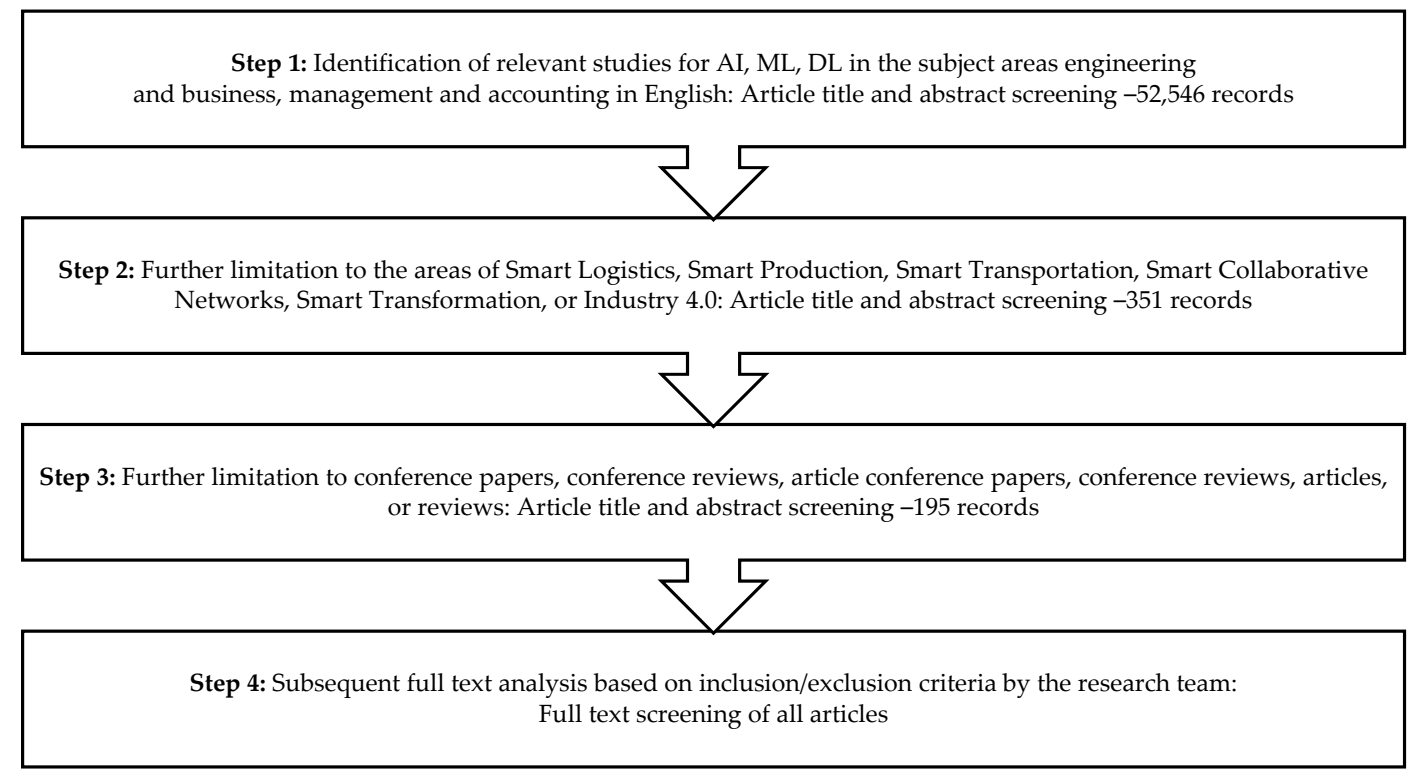

Figure 1. Process steps of the systematic literature review.

In the first step, the authors identified the relevant literature for $\mathrm{AI}, \mathrm{ML}$, and $\mathrm{DL}$ in the subject areas of engineering and business, management and accounting by screening the article title, abstract, and keywords. In this step, the authors included all kinds of document types and restricted them to the language English. This first approach was primarily used to get a first impression of the current state of research. Therefore, the authors limited the timeframe of the research studies to the period from 1 January 2014 to 1 January 2019. In general, this process resulted in 52,546 identified studies.

In the second step, the authors additionally focused on studies that are related to the areas of Smart Logistics, Smart Production, Smart Transportation, Smart Collaborative Networks, Smart Transformation, or Industry 4.0. Therefore, we limited the previously identified 52,546 papers to the terms Smart Logistics, Smart Production, Smart Transportation, Smart Collaborative Networks, Smart Transformation, or Industry 4.0, which resulted in a total of 351 identified papers. Moreover, the authors have computed a ranking of all identified keywords, which was used to validate the meta-search query for the ongoing database research. No significant keywords were missing in our research strategy. 
In the third step, the research was limited to conference papers, conference reviews, articles, or reviews to consider only high-quality studies. In sum, the final meta-search query was formulated as follows: (TITLE-ABS-KEY ("artificial intelligence" OR "machine learning" OR "deep learning") AND TITLE-ABS-KEY ("smart logistics" OR "smart production" OR "smart transportation" OR "smart collaborative networks" OR "smart transformation" OR "industry 4.0")) AND (LIMIT-TO (DOCTYPE, “cp") OR LIMIT-TO (DOCTYPE, “ar") OR LIMIT-TO (DOCTYPE, “cr") OR LIMIT-TO (DOCTYPE, "re")) AND (LIMIT-TO (SUBJAREA, “ENGI”) OR LIMIT-TO (SUBJAREA, “BUSI")) AND (LIMIT-TO (PUBYEAR, 2019) OR LIMIT-TO (PUBYEAR, 2018) OR LIMIT-TO (PUBYEAR, 2017) OR LIMIT-TO (PUBYEAR, 2016) OR LIMIT-TO (PUBYEAR, 2015) OR LIMIT-TO (PUBYEAR, 2014)) AND (LIMIT-TO (LANGUAGE, “English”)).

The following Table 1 displays the characteristics of the search string.

Table 1. Characteristics of the search string.

\begin{tabular}{ccccc}
\hline Keywords (1) & Keywords (2) & Language & Timeframe $^{\text {Paper Type }}$ \\
\hline Artificial & Smart Logistics & - & - & CP or CR \\
Intelligence & Smart Production & English & $2014-2019$ \\
Machine Learning & Smart Transportation & - & - & AR \\
Deep Learning & Smart Collaborative Networks & - & - & - \\
- & Smart Transformation & Industry 4.0 & - & - \\
- & 1 Conference Proceedings (CP), Conference Reviews (CR), Articles (AR), Reviews (RE).
\end{tabular}

As a result, the authors have identified 195 papers as the basis for the further research process.

\subsection{Validation of the Research Results}

Based on the quality criteria of empirical research (validity, reliability, objectivity, and generalizability) the authors emphasize that the identification process is one of the most crucial elements within the SLR [17]. Therefore, we ensured the quality of the research results by coding the identified studies with the score " 1 " (high appropriateness), the score "2" (medium appropriateness), or the score "3" (low appropriateness).

The screening was carried out in two steps by three independent Postdoc-researchers. In the first step, the screening focused only on the title and abstract of the studies. In the second step, the full text of the study was completely evaluated by the research team. Moreover, the reliability was calculated by evaluating significant differences in the scorings. Papers without significant differences were directly included or excluded in/from the research process. Papers with significant differences were reevaluated by the research team to get unambiguous research results.

By reviewing the title and abstract of the 195 papers, we identified 103 relevant papers for the area of Smart Logistics and 148 for the area Smart Production. In the area of Smart Logistics, out of the 103 studies, 33 were assigned as having high appropriateness, whereas in the area of Smart Production, 44 were assigned as having high appropriateness for this research study and the subsequent secondary data analyses. Table 2 displays the total results of the SLR.

Table 2. Total research results of the systematic literature review (SLR).

\begin{tabular}{ccc}
\hline No./Appropriateness & Smart Logistics & Smart Production \\
\hline Total studies & 103 & 148 \\
High appropriateness & 33 & 44 \\
Medium appropriateness & 52 & 46 \\
Low appropriateness & 18 & 18 \\
\hline
\end{tabular}


In this paper, we aim to analyze the current state-of-the-art regarding the use of artificial intelligence, machine learning, and deep learning in logistics. Therefore, we consider in the following sections only the papers identified for Smart Logistics.

\section{Results}

In this section, the authors analyze the descriptive findings of the SLR. Moreover, the full texts of the identified papers will be discussed in the content analysis section.

\subsection{Descriptive Analysis}

Based on the previously identified total number of 52,546 papers regarding the application of AI, ML, and DL in various scientific disciplines, 103 papers were finally assigned to the area of Smart Logistics in industrial enterprises and therefore rated as relevant for further analysis within this research study. Table 3 shows the distribution of the appropriateness of the identified studies, which was evaluated by screening the title and the abstract of the respective studies.

Table 3. Distribution of appropriateness of studies.

\begin{tabular}{ccc}
\hline No./Appropriateness & Records & Records (\%) \\
\hline Total studies & 103 & 100.00 \\
High appropriateness & 33 & 32.04 \\
Medium appropriateness & 52 & 50.49 \\
Low appropriateness & 18 & 17.48 \\
\hline
\end{tabular}

Out of the identified 103 full texts in the area of Smart Logistics, 33 papers (32.04\%) were classified as papers with high appropriateness, 52 papers (50.49\%) were classified as papers with medium appropriateness, and 18 papers $(17.48 \%)$ were classified as papers with low appropriateness regarding the aim of this research study.

Table 4 shows the distribution of document types based on the identified 103 full papers in the area of Smart Logistics.

Table 4. Distribution of document types.

\begin{tabular}{ccc}
\hline Type of Document & Records & Records (\%) \\
\hline Conference Proceedings & 63 & 61.17 \\
Conference Reviews & 0 & 0 \\
Articles & 38 & 36.89 \\
Reviews & 2 & 1.94 \\
\hline
\end{tabular}

A total of 63 papers (61.17\%) are conference proceedings, 38 (36.89\%) are articles, and $2(1.94 \%)$ are reviews. No conference reviews were identified in the final sample. The following Figure 2 shows the development of the relevant research studies from 2014-2019.

Three papers $(2.91 \%)$ were published in 2014 , four papers $(3.88 \%)$ were published in 2015 , six papers $(5.83 \%)$ were published in 2016,29 papers $(28.16 \%)$ were published in 2017, and 61 studies $(59.22 \%)$ were published in 2018. In general, there is still an increasing trend of relevant studies regarding the application of $\mathrm{AI}, \mathrm{ML}$, and DL in the area of Smart Logistics in industrial enterprises.

The following Table 5 displays the distribution of sources of the identified studies. Most of the studies were published in Lecture Notes in Computer Science, Advances in Intelligent Systems and Computing, IFAC-Papers Online, and IFIP Advances in Information and Communication Technology. 


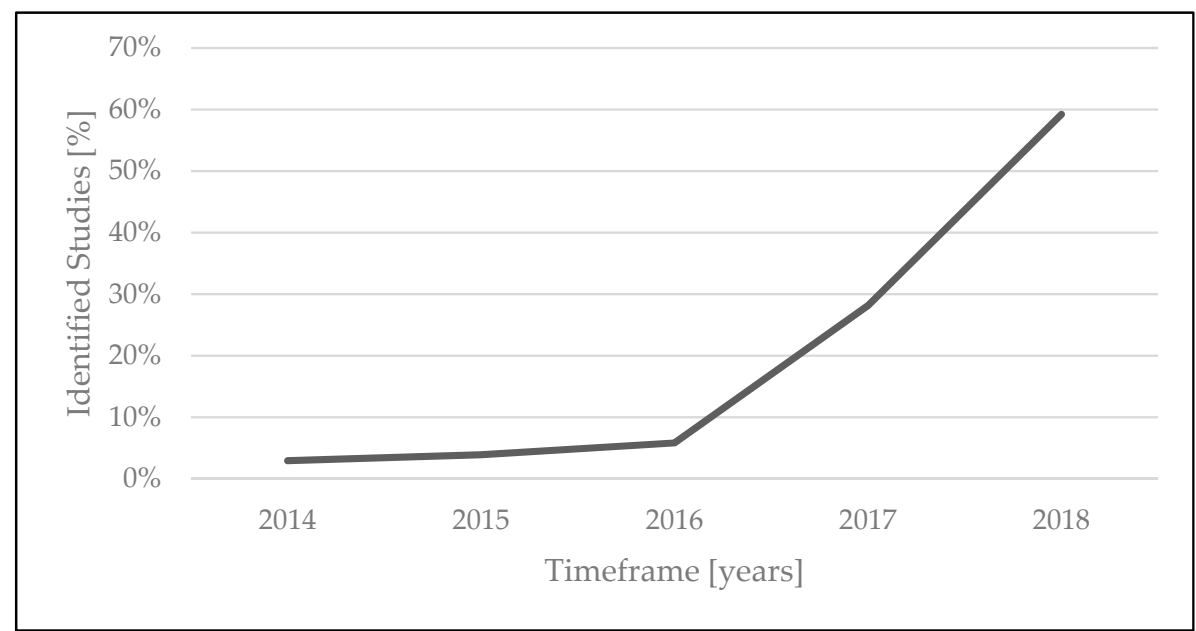

Figure 2. Development of the relevant research studies 2014-2018.

Table 5. Distribution of the identified studies.

\begin{tabular}{ccc}
\hline Source & Records & Records (\%) \\
\hline Lecture Notes in Computer Science & 8 & 7.77 \\
Advances in Intelligent Systems and Computing & 5 & 4.85 \\
IFAC-Papers Online & 5 & 4.85 \\
IFIP Advances in Information and Communication Technology & 4 & 3.88 \\
Journal of Manufacturing Systems & 3 & 2.91 \\
Procedia CIRP & 3 & 2.91 \\
Procedia Manufacturing & 3 & 2.91 \\
CEUR Workshop Proceedings & 2 & 1.94 \\
Computers in Industry & 2 & 1.94 \\
IEEE Intelligent Systems & 2 & 1.94 \\
Journal of Big Data & 2 & 1.94 \\
Manufacturing Letters & 2 & 1.94 \\
IEEE Transactions on Industrial Informatics & 2 & 1.94 \\
2018 IEEE Global Communications Conference & 2 & 1.94 \\
Others & 58 & 56.31 \\
\hline
\end{tabular}

The following Figure 3 shows an overview of the identified research collaborations based on the systematic literature review.

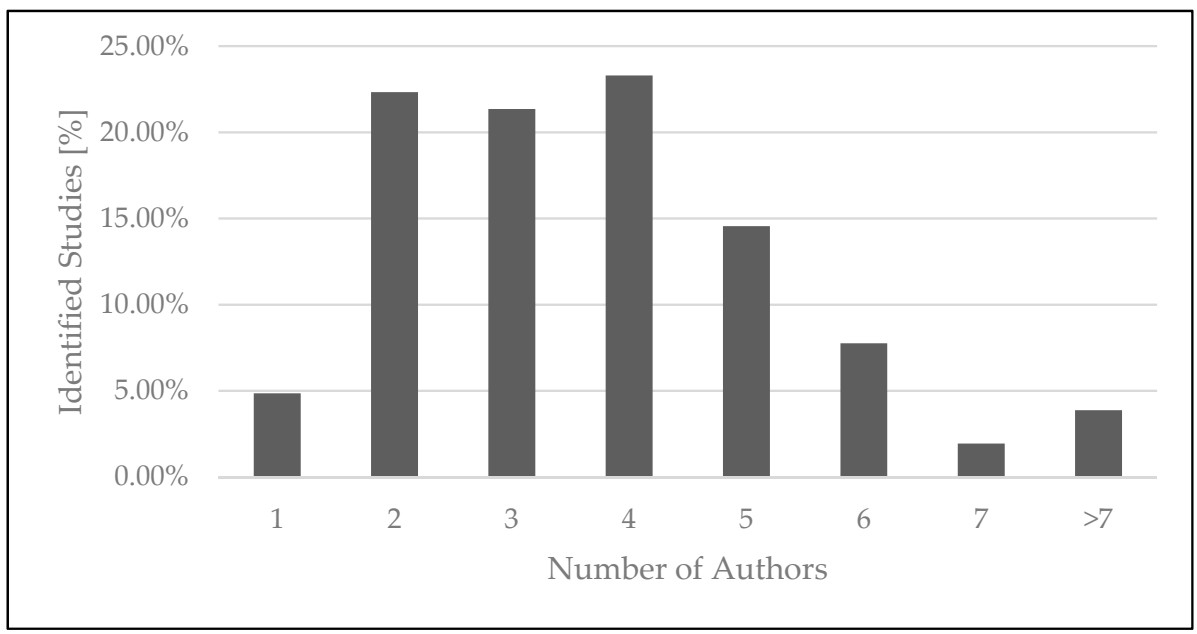

Figure 3. Overview of the identified research collaborations. 
Five papers $(4.85 \%)$ were published by one author, 23 papers $(22.33 \%)$ were published by two authors, 22 papers $(21.36 \%)$ were published by three authors, 24 papers $(23.30 \%)$ were published by four authors, 15 papers $(14.56 \%)$ were published by five authors, eight papers $(7.77 \%)$ were published by six authors, two papers $(1.94 \%)$ were published by seven authors, and four papers $(3.88 \%)$ were published by more than seven authors.

In the next step, the authors performed a keyword analysis by extracting the author keywords and index keywords of the relevant papers from the Scopus database. The results are displayed in the following Figure 4.
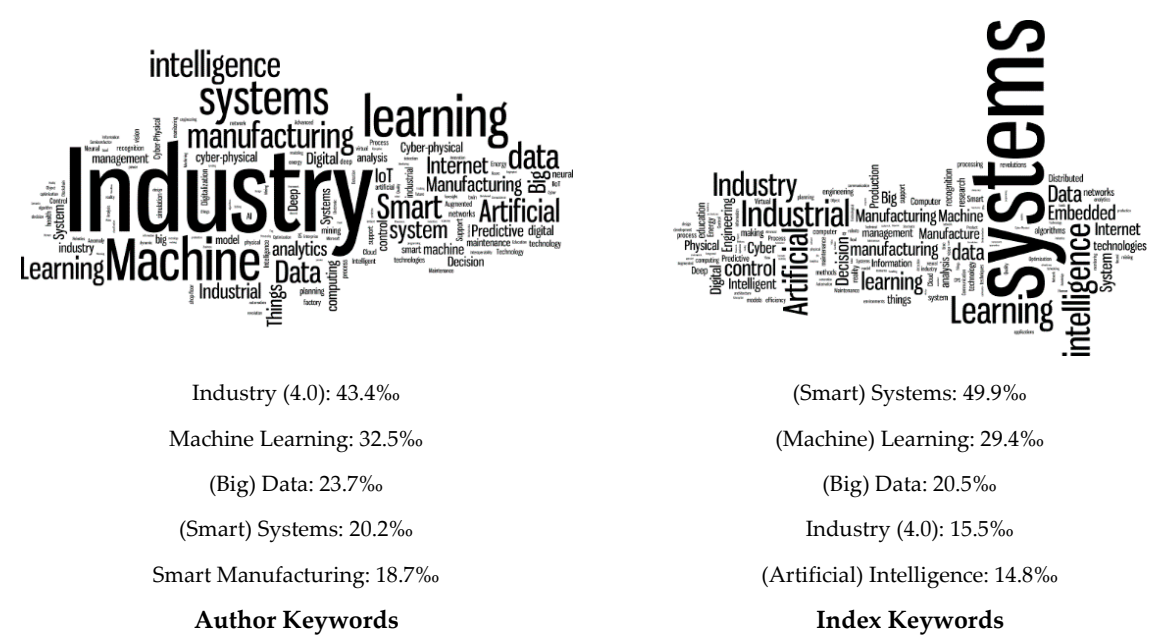

Figure 4. Analysis of keywords.

The keywords were analyzed by using the software packages IBM SPSS Statistics 24 (IBM, New York, NY, USA) and Wordle (www.wordle.net, California, CA, USA). Thereby, the size of the words and letters reflects the frequency of the keywords from the final sample of 103 full papers. As expected, the most important author keywords are "Industry (4.0)", "Machine Learning", "(Big) Data", "(Smart) Systems", and "Smart Manufacturing". Moreover, the top-ranked index keywords are "(Smart) Systems", "(Machine) Learning", "(Big) Data", "Industry (4.0)", and "(Artificial) Intelligence".

The following Figure 5 displays the classification of the relevant research study by the type of study, divided into Case Study (CS), Conceptual Approach (CA), Experiment (EX), and Literature Review (LR). The classification is based on the content analysis and subsequent assignment of the works to one main type of study by the research team.

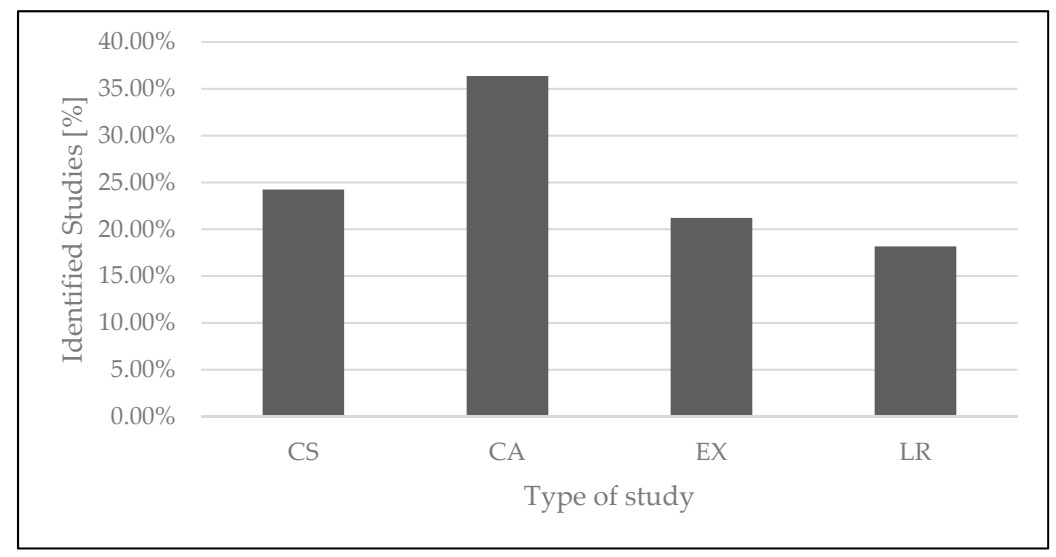

Figure 5. Classification of the relevant research studies per type of study-Case Study (CS), Conceptual Approach (CA), Experiment (EX), and Literature Review (LR). 
From the identified 33 articles with high appropriateness, eight (24.24\%) articles can be classified as case articles (CS), 12 (36.36\%) articles can be classified as conceptual approaches (CA), seven $(21.21 \%)$ articles can be classified as an experiment (EX), and six (18.18\%) articles can be classified as literature review (LR).

\subsection{Content Analysis}

In this section, the authors analyze the full texts of the identified papers. Therefore, Tables 6 and 7 display the comprehensive results from the systematic literature review by briefly summarizing the clusters, the main references, the number of records, and the percentage of records in Table 6, as well as the authors, the type of the study, the clusters, and the main content of each identified work in Table 7. The research team conducted a profound content analysis to categorize the selected literature into similar clusters.

Table 6. Classification of the identified studies.

\begin{tabular}{ccccc}
\hline No. & Cluster & Main References & Records & Records (\%) \\
\hline 1 & Strategic and Tactical Process Optimization & {$[25-28]$} & 4 & $12.12 \%$ \\
2 & Cyber-Physical Systems in Logistics & {$[29-35]$} & 7 & $21.21 \%$ \\
3 & Predictive Maintenance & {$[36-41]$} & 7 & $21.21 \%$ \\
4 & Hybrid Decision Support Systems & {$[42-44]$} & 3 & $9.09 \%$ \\
5 & Production Planning and Control Systems & {$[45-49]$} & 4 & $12.12 \%$ \\
6 & Improvement of Operational Processes in Logistics & {$[50-53]$} & 4 & $12.12 \%$ \\
7 & Intelligent Transport Logistics & {$[54-57]$} & 4 & $12.12 \%$ \\
\hline
\end{tabular}

The results were further aggregated to the following five clusters:

(1) Strategic and tactical process optimization;

(2) Cyber-physical systems in logistics;

(3) Predictive maintenance;

(4) Hybrid decision support systems;

(5) Production planning and control systems;

(6) Improvement of operational processes in logistics;

(7) Intelligent transport logistics.

The following Table 6 displays the results of the classification of five clusters regarding the application of AI, ML, and DL in the area of Smart Logistics in industrial enterprises.

In the following paragraphs, we will describe and summarize the content of the identified studies for each of the defined clusters.

\subsubsection{Strategic and Tactical Process Optimization}

A total of $12.12 \%$ of the identified articles were assigned to the cluster "strategic and tactical process optimization". Gursch et al. review learning systems for management support in the area of condition monitoring and process control of enterprises. Furthermore, the authors state that ML can provide solutions in the fields of optimization, automation, and human support by handling complex problems that cannot be solved via static and non-adaptive computer programs [25]. Brodsky et al. focus on the application of decision analytics, for example, for the development of decision guidelines in strategic and tactical reasoning. Furthermore, the guidelines can be used to perform monitoring, analysis, planning, and optimization tasks within manufacturing and logistics processes [26]. Qu et al. propose a general computational reasoning and learning framework under realistic conditions. The approach explains how to realize smart processes from a formal and data-orientated methodological point of view [27]. Bonino and Vergori introduce a concept and architecture for connecting inner and outer value chains in modern factories by using ML, AI, and IoT technologies. Thereby, the authors highlight 
how modern IT-systems will innovate and optimize daily processes in production and logistics by implementing multi-agent systems and ML technologies [28].

\subsubsection{Cyber-Physical Systems in Logistics}

A total of $21.21 \%$ of the identified articles were assigned to the cluster "frameworks for CPS in logistics". In this context, Peres et al. introduce an IDARTS framework for intelligent data analysis and real-time supervision as a guideline for the implementation of scalable, flexible, and pluggable analyses within production environments. The framework can be used to translate data into business advantages in fields such as predictive maintenance, quality control, production, and logistics through the implementation of CPS based on cloud computing. The framework further includes technologies of data acquisition, ML, and run-time reasoning for production and logistics processes [29]. Guo et al. describe a method for learning from imbalanced machinery data by transferring visual elements detectors. The authors propose a methodology to organize collected sensor data into image form and utilize visual element detectors based on convolutional neuronal networks (CNN) [30]. Ferrer et al. present a concept for the implementation the adaptation of CPS by focusing on the production line, logistics, and facilities based on advanced data analytics, machine-to-machine IoT protocols, machine learning, knowledge representation algorithms, and cloud-based platforms in (smart) manufacturing environments. Moreover, they present a scenario for the implementation of CPS in the course of a pilot study [31].

Thalmann et al. describe new analytic methods and tools for the optimization of industrial processes. The projects aim to develop a set of tools, e.g., algorithms, analytic machinery, planning approaches, and visualization for industrial process improvement based on data analytics [32]. Morozov et al. present an adaptation approach for CPS, namely the Formal Concept Analysis (FCA), which includes AI and ML for the structuring of knowledge and the optimization of the CPS interoperability [33]. Marella and Mecalla and Marella et al. introduce a process management system (PMS) for cyber-physical processes (CPPs) and smart process management (SmartPM). The system can be used to automatically adapt processes by using $\mathrm{AI}$ and cognitive computing based on a large amount of data [34,35].

\subsubsection{Predictive Maintenance}

A total of $21.21 \%$ of the identified articles were assigned to the cluster "predictive maintenance". Thereby, Subakti and Jiang propose the design, development, and implementation of an augmented reality system for machines in smart factories. A deep learning image detection module identifies different machines and IoT allows the machines to report machine settings and machine states to a cloud-based server [36]. Susto et al. describe a methodology to derive the health factor of machines by applying a Monte Carlo approach based on particle filtering techniques to a real industrial predictive maintenance problem in the semiconductor industry [37]. Wang and Wang discuss the impact of AI on the future of predictive maintenance by focusing on DL technology. Thereby, they state a list of state-of-the-art algorithms in the field of predictive maintenance, e.g., deep feedforward networks, long short-term memory, convolutional networks, deep belief networks, etc., which can be considered as key success factors for future industries [38].

Klein and Bergman propose an approach for the generation of predictive maintenance data for ML investigations by using a Fischertechnik model factory equipped with several sensors. The dataset will be published and can be used in future investigations and for the further development of ML and DL approaches as well [39]. Cho et al. introduce a hybrid ML approach for predictive maintenance in smart factories. The approach combines unsupervised learning with semi-supervised learning to provide data-driven decision support [40]. Wuest et al. review the application of ML techniques in manufacturing in the areas of monitoring and image recognition. Thereby, they distinguish between supervised learning, unsupervised learning, and reinforcement learning, which can be used as powerful toolsets within manufacturing environments [41]. 


\subsubsection{Hybrid Decision Support Systems}

A total of $9.09 \%$ of the identified articles were assigned to the cluster "decision support systems and man-machine interaction". In this context, Terziyan et al. introduce Pi-Mind technology as a mixture of human-expert-driven decision-making and AI-driven decision-making approaches for smart manufacturing processes based on AI and ML technologies. In many cases, this hybrid approach outperforms rational decision-making processes by human operators [42]. Venkatapathy et al. and Zeidler et al. describe a basic concept of a hybrid network for the usage of human and machine synergies in the intra-logistics. Thereby, they focus on optical reference systems, radio reference systems, laser project systems, virtual reality systems, robot systems, LR-WPAN, and other wireless network systems, and networked computational systems [43,44].

\subsubsection{Production Planning and Control Systems}

A total of $12.12 \%$ of the identified articles were assigned to the cluster "production planning and control systems". Lolli et al. present an approach for a multi-criteria-based classification of inventory based on machine learning techniques. Thereby, the authors achieve a reduction of simulation effort by using supervised classifiers from the field of ML [45]. He et al. review a set of multi-objective swarm intelligence algorithms for flow shop scheduling problems. Besides conventional algorithms, new ML-based approaches are also presented in this paper. The performance of the various algorithms can be evaluated by the minimum distance to the Pareto-optimal front, the goodness of the distribution, and the maximum spread [46]. Zhang et al. systematically review the literature on job shop scheduling research in the context of Industry 4.0, based on ML, AI, and DL technologies. The algorithms were further classified in exact optimization methods, e.g., efficient rule approach, mathematical programming approach, branch and bound methods, and approximate methods (e.g., constructive methods, artificial intelligence methods, local search methods, and meta-heuristic methods) [47].

Gomes et al. develop an ambient intelligent-based decision support system for production planning and control based on ML that assists in the creation of standard work procedures that assure production quantity and efficiency by using ambient intelligence, optimization heuristics, and ML [48]. Luetkehoff et al. develop a self-learning production control system by using algorithms of AI. The developed approach presents a new platform-based concept to collect and analyze data by using self-learning algorithms. The patterns can be used for a prediction of future system behavior [49].

\subsubsection{Improvement of Operational Processes in Logistics}

A total of $12.12 \%$ of the identified articles were assigned to the cluster "improvement of operational processes in logistics". Wen et al. discuss the application of swarm robotics in the area of Smart Logistics by outlining some possibilities and fields of application, e.g., smart warehousing, smart delivery, route tracking, precise supply chains, green logistics, and smart ICTs, in the next area of modern logistics [50]. Laux et al. describe a reflection-based sound localization system that is based on ML approaches and can be used for indoor localization and object tracking [51].

Ademujimi et al. review the current literature on ML techniques in manufacturing by focusing on techniques, e.g., Bayesian networks, the artificial neural network, the support vector machine, and the hidden Markov model for the optimization of manufacturing fault diagnosis [52]. Teschemacher and Reinhart develop an ant colony optimization algorithm to enable dynamic milk runs in logistics to reduce the number of necessary vehicles in long-term optimization approaches [53]. 
Table 7. Systematic literature review (SLR) on artificial intelligence (AI), machine learning (ML), and deep learning (DL) in Smart Logistics.

\begin{tabular}{|c|c|c|c|c|c|}
\hline No. & Ref. No. & Author(s) and Year & Type of Study & Cluster & Content \\
\hline 1 & [29] & Peres et al., 2018 & Case Study & Cyber-Physical Systems in Logistics & $\begin{array}{l}\text { IDARTS framework for intelligent data analysis and real-time supervision as } \\
\text { a guideline for the implementation of scalable, flexible, and pluggable } \\
\text { analyses within production environments based on cyber-physical systems } \\
\text { (CPS) and cloud computing. }\end{array}$ \\
\hline 2 & {$[30]$} & Guo et al., 2018 & Experiment & Cyber-Physical Systems in Logistics & $\begin{array}{l}\text { Methodology to organize collected sensor data into image form and utilize } \\
\text { visual element detectors based on convolutional neuronal networks (CNN). }\end{array}$ \\
\hline 3 & [31] & Ferrer et al., 2018 & Case Study & Cyber-Physical Systems in Logistics & $\begin{array}{l}\text { Concept and exemplary case study for the implementation of CPS by } \\
\text { focusing on the production line, logistics, and facilities in (smart) } \\
\text { manufacturing companies. }\end{array}$ \\
\hline 4 & [32] & Thalmann et al., 2018 & Conceptual Approach & Cyber-Physical Systems in Logistics & $\begin{array}{l}\text { Concept and resp. discussion of a set of tools, e.g., algorithms, analytic } \\
\text { machinery, planning approaches, and visualization for industrial process } \\
\text { improvement based on data analytics. }\end{array}$ \\
\hline 5 & {$[50]$} & Wen et al., 2018 & Conceptual Approach & Improvement of Operational Processes & $\begin{array}{l}\text { Application of swarm robotics in the area of Smart Logistics (smart } \\
\text { warehousing, smart delivery, route tracking, precise supply chains, green } \\
\text { logistics, and smart information and communication technologies (ICTs), } \\
\text { etc.). }\end{array}$ \\
\hline 6 & [42] & Terziyan et al., 2018 & Conceptual Approach & Hybrid Decision Support Systems & $\begin{array}{l}\text { Pi-Mind as a mixture of human-expert-driven and AI-driven } \\
\text { decision-making approaches based on AI and ML. }\end{array}$ \\
\hline 7 & [36] & Subakti \& Jiang, 2018 & Case Study & Predictive Maintenance & $\begin{array}{l}\text { Usage of AR and ML for machine detection and the provision of machine } \\
\text { data in smart factories. }\end{array}$ \\
\hline 8 & [51] & Laux et al., 2018 & Experiment & Improvement of Operational Processes & Reflection-based sound localization system based on ML approaches. \\
\hline 9 & [37] & Susto et al., 2018 & Experiment & Predictive Maintenance & $\begin{array}{l}\text { Predictive maintenance model based on a numerical Monte Carlo approach } \\
\text { with particle filtering techniques. }\end{array}$ \\
\hline 10 & [38] & Wang \& Wang, 2018 & Literature Review & Predictive Maintenance & Conceptual discussion of $\mathrm{AI}$ and $\mathrm{DL}$ in predictive maintenance applications. \\
\hline 11 & [39] & Klein \& Bergmann, 2018 & Case Study & Predictive Maintenance & $\begin{array}{l}\text { Approach for the generation of predictive maintenance data for ML } \\
\text { investigations by using a Fischertechnik model factory. }\end{array}$ \\
\hline 12 & [45] & Lolli et al., 2019 & Experiment & Production Planning and Control Systems & $\begin{array}{l}\text { Approach for a multi-criteria-based classification of inventory based on } \\
\text { machine learning techniques. }\end{array}$ \\
\hline 13 & [33] & Morozov et al., 2018 & Conceptual Approach & Cyber-Physical Systems in Logistics & $\begin{array}{l}\text { Adaptation approach for CPS, namely the formal concept analysis (FCA), } \\
\text { which includes AI and ML for the structuring of knowledge and the } \\
\text { optimization of the CPS interoperability. }\end{array}$ \\
\hline 14 & [46] & He et al., 2018 & Literature Review & Production Planning and Control Systems & $\begin{array}{l}\text { Review swarm intelligence algorithms for multi-objective flow shop } \\
\text { scheduling problems. }\end{array}$ \\
\hline 15 & [40] & Cho et al., 2018 & Case Study & Predictive Maintenance & $\begin{array}{l}\text { Hybrid ML approach for predictive maintenance, which combines } \\
\text { unsupervised learning with supervised learning in smart factories. }\end{array}$ \\
\hline
\end{tabular}


Table 7. Cont.

\begin{tabular}{|c|c|c|c|c|c|}
\hline No. & Ref. No. & Author(s) and Year & Type of Study & Cluster & Content \\
\hline 16 & [34] & Marrella \& Mecella, 2018 & Conceptual Approach & Cyber-Physical Systems in Logistics & $\begin{array}{l}\text { Process management system (PMS) for cyber-physical processes (CPPs) and } \\
\text { smart process management (SmartPM) based on AI and cognitive } \\
\text { computing. }\end{array}$ \\
\hline 17 & [35] & Marrella et al., 2018 & Case Study & Cyber-Physical Systems in Logistics & $\begin{array}{l}\text { Process management system (PMS) for cyber-physical processes (CPPs) and } \\
\text { smart process management (SmartPM) based on AI and cognitive } \\
\text { computing. }\end{array}$ \\
\hline 18 & [43] & Venkatapathy et al., 2017 & Conceptual Approach & Hybrid Decision Support Systems & $\begin{array}{l}\text { Concept of a hybrid network for the usage of human and machine synergies } \\
\text { in the intra-logistics. }\end{array}$ \\
\hline 19 & [44] & Zeidler et al., 2017 & Conceptual Approach & Hybrid Decision Support Systems & $\begin{array}{l}\text { Concept of a hybrid network for the usage of human and machine synergies } \\
\text { in the intra-logistics. }\end{array}$ \\
\hline 20 & [28] & Bonino \& Vergori, 2017 & Case Study & Strategic and Tactical Process Optimization & $\begin{array}{l}\text { Architecture for connecting inner and outer value chains in modern factories } \\
\text { by using ML, AI, and IoT technologies. }\end{array}$ \\
\hline 21 & [47] & Zhang et al., 2019 & Literature Review & Production Planning and Control Systems & $\begin{array}{l}\text { Review of literature on job shop scheduling research in the context of } \\
\text { Industry } 4.0 \text {. }\end{array}$ \\
\hline 22 & [52] & Ademujimi et al., 2017 & Literature Review & Improvement of Operational Processes & Review of literature on ML techniques in manufacturing. \\
\hline 23 & [25] & Gursch et al., 2016 & Literature Review & Strategic and Tactical Process Optimization & $\begin{array}{l}\text { Review of learning systems for management support in the areas of } \\
\text { condition monitoring and process control, scheduling, and predictive } \\
\text { maintenance. }\end{array}$ \\
\hline 24 & [48] & Gomes et al., 2017 & Conceptual Approach & Production Planning and Control Systems & $\begin{array}{l}\text { Ambient intelligent-based decision support system for production planning } \\
\text { and control based on ML. }\end{array}$ \\
\hline 25 & [49] & Luetkehoff et al., 2017 & Conceptual Approach & Production Planning and Control Systems & $\begin{array}{l}\text { Development of a self-learning production control system by using } \\
\text { algorithms of AI. }\end{array}$ \\
\hline 26 & [53] & $\begin{array}{l}\text { Teschemacher \& Reinhart, } \\
2017\end{array}$ & Experiment & Improvement of Operational Processes & $\begin{array}{l}\text { Development of an ant colony optimization algorithm to enable dynamic } \\
\text { milk runs in logistics. }\end{array}$ \\
\hline 27 & [41] & Wuest et al., 2016 & Literature Review & Predictive Maintenance & $\begin{array}{l}\text { ML techniques in manufacturing in the areas of monitoring, and image } \\
\text { recognition. }\end{array}$ \\
\hline 28 & [26] & Brodsky et al., 2014 & Conceptual Approach & Strategic and Tactical Process Optimization & Application of decision analytics in smart manufacturing. \\
\hline 29 & [27] & Qu et al., 2014 & Conceptual Approach & Strategic and Tactical Process Optimization & $\begin{array}{l}\text { General computational reasoning and learning framework for smart } \\
\text { manufacturing. }\end{array}$ \\
\hline 30 & [54] & Li et al., 2018 & Experiment & Intelligent Transport Logistics & Intelligent transport system based on $\mathrm{AI}, \mathrm{ML}$, and DL technologies. \\
\hline 31 & [55] & Cheng et al., 2017 & Case Study & Intelligent Transport Logistics & Fuzzy-group-based control for smart transportation processes. \\
\hline 32 & [56] & Li et al., 2015 & Experiment & Intelligent Transport Logistics & $\begin{array}{l}\text { Analyses and optimization of traffic conditions based on internet of things } \\
\text { (IoT) techniques. }\end{array}$ \\
\hline 33 & [57] & Edelstein, 2014 & Conceptual Approach & Intelligent Transport Logistics & Smart transport management systems through ICT. \\
\hline
\end{tabular}




\subsubsection{Intelligent Transport Logistics}

A total of $12.12 \%$ of the identified articles were assigned to the cluster "intelligent transport logistics". Li et al. (2018) introduce an intelligent transport system that combines information technology, data communication technology, electronic sensing technology, global positioning technology, geographical information system technology, computer processing technology, and system engineering technology to a real-time, accurate, efficient and intelligent transportation management system based on deep belief network models (DBN) and support vector regression classifier (SVR) [54]. Cheng et al. (2017) discuss a fuzzy-group-based control for smart transportations, which reduces waiting time and improves the performance by up to $40 \%$ [55]. Li et al. (2015) analyze traffic conditions based on IoT techniques by applying numerical techniques from data mining and machine learning approaches [56]. Edelstein (2014) outlines the potentials of smarter transport management through ICT in terms of operational efficiency, reduced costs, and an enhanced entrepreneurial environment for the staff to develop and implement process innovations by using integrated multimodal transport systems [57].

\section{Conceptual Framework for the Application of AI, ML, and DL in Smart Logistics}

\subsection{Framework for the Application AI, ML, and DL in Smart Logistics}

In this paper, the authors have identified five clusters that can be amalgamated to a conceptual framework for the application of AI, ML, and DL in Smart Logistics in industrial enterprises. Figure 6 illustrates the developed clusters, namely, "frameworks for CPS in logistics", "predictive maintenance", "decision support systems and man-machine interaction", "production planning and control systems", and "improvement of operational processes in logistics". According to the results of the content analysis, the research team mapped to each of the identified clusters of relevant methods and instruments indicated in the literature.

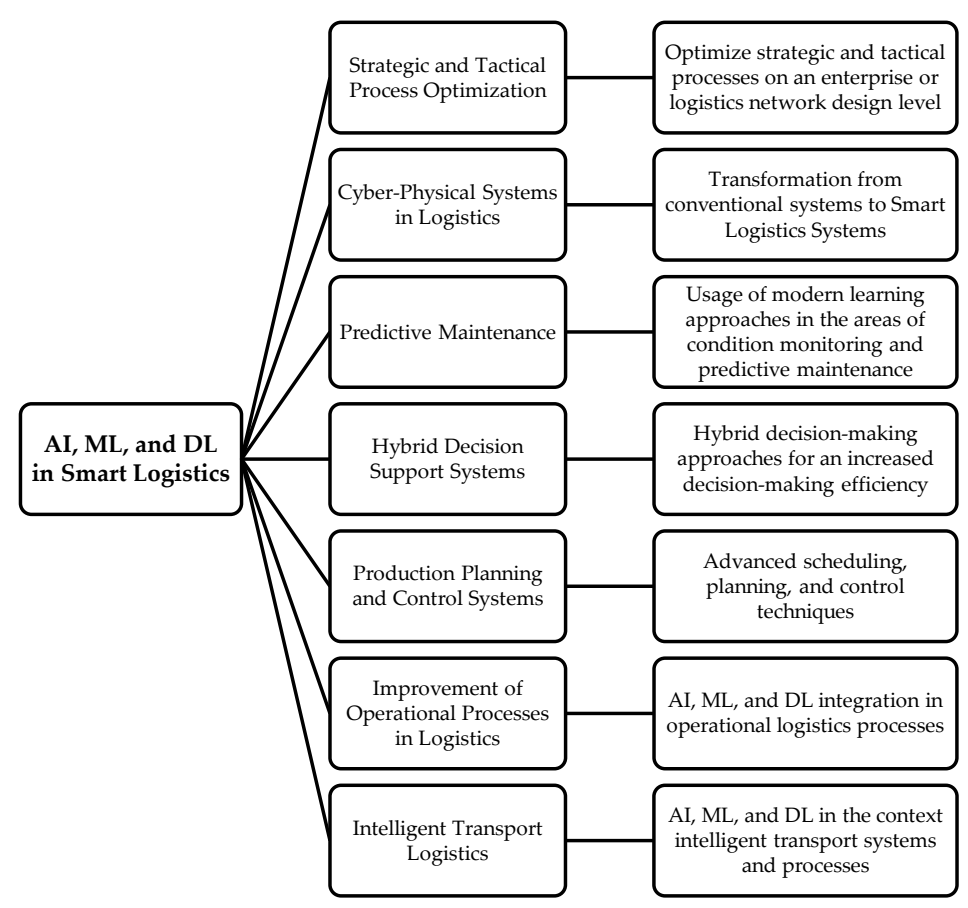

Figure 6. Conceptual framework for AI, ML, and DL in Smart Logistics.

Cluster 1, "strategic and tactical process optimization", concentrates on the application of AI, ML, and DL methods to optimize strategic and tactical processes on an enterprise or logistics network design level. Based on learning systems for management support, so-called management information 
systems can be enriched with intelligence, therefore providing not only data, information, and key performance indicators but also preparing and make decisions on a strategic and tactical level [25-28]. Further progress in such strategic and tactical process optimization will be of significant importance for large companies operating in different countries.

Cluster 2, "cyber-physical systems in logistics", describes opportunities for the development from a conventional logistics system to a Smart Logistics system based on actors and sensors for real-time data analysis and enhanced knowledge management through state-of-the-art learning approaches. CPS can be used to improve the quality of production and logistics processes, which further affects the overall efficiency of the industrial enterprise. Moreover, CPS will lead to increased connectivity, consistent digitalization, better modeling techniques, more flexibility, and higher versatility and reusability of systems and systems' components [29-35].

Cluster 3, "predictive maintenance", focuses on the usage of learning approaches in the areas of condition monitoring and predictive maintenance. Thereby, a multitude of studies suggests the application of recent AL, ML, and DL approaches for the continuous reporting of machine settings, machine states, and quality parameter settings. Based on real-time data, enhanced knowledge can be used for further predictive analysis regarding a strategic and pro-active plant maintenance strategy for production and logistics processes [36-41].

Cluster 4, "hybrid decision support systems", describes the improvement of non-automated and therefore human-centered decision-making processes by using learnable support systems. In this context, decision-relevant information will be automatically collected, aggregated, and pre-analyzed by AI, ML, and DL technologies. In many cases, these hybrid decision-making processes outperform purely rational decision-making processes [42-44,58].

Cluster 5, "production planning and control systems", introduces new opportunities for advanced planning and control approaches in the research fields of inventory management, flow shop problems, traditional job shop scheduling problems, production process optimization, and the self-learning abilities of modern production planning and control systems based on the application of AI, ML, and DL technologies [45-49].

Cluster 6, "improvement of operational processes in logistics", outlines various possibilities for the enhancement of operational processes in logistics by applying AI, ML, and DL technologies. Thereby, swarm robotics can be used to optimize smart warehouses, sound location systems can increase the efficiency of identification and tracking approaches, AI-based algorithms ensure holistic manufacturing fault diagnosis, and ant colony optimization approaches enable the optimization of milk runs in logistics problems [50-53].

Cluster 7, "intelligent transport logistics", analyzes the application of AI, ML, and DL technologies in intelligent transport systems and intelligent transport processes. In this context, the performance of transport logistics can be increased by applying AI-based methods in combination with state-of-the-art approaches based on the usage of information technology, data communication technology, electronic sensing technology, global positioning technology, geographical information system technology, computer processing technology, and system engineering technology [54-57].

\subsection{Practical Examples}

In this section, we looked for practical examples for each of the identified clusters or applications of $\mathrm{AI}, \mathrm{ML}$, and DL in logistics. This analysis should provide an overview of how the proposed framework can be transferred into practice and what are the practical implications for managers of companies.

Aitheon presents on his website one of the first AI-driven project management tools. The project management AI generates a straightforward list for those who want to be in the general work process without the need to understand or learn the depths of project management tools. The tool generates prioritized and grouped tasks by artificial intelligence. An AI-based sketchboard visually organizes information to show the relationships amongst the pieces of the whole project. This helps to create 
a vision of complex ideas, concepts, or projects, which is generated into tasks viewable in Gantt or Kanban views [59].

DHL research describe their vision of digital twins in logistics. Artificial intelligence has given digital twins and cyber-physical systems a big push in creating new value. Today, all the data DHL has from sensors, historical performance, and inputs about behavior lends itself to being linked to spatial models and to predict future behavior by changing different inputs. The data and prediction capabilities of AI make the spatial model come alive [60].

Presenso is a predictive maintenance software using machine learning and deep learning algorithms to drive precise and continuous failure prediction. With the use of software, logistics companies can achieve operational savings through full predictive maintenance aimed at yield optimization. The system collects large amounts of data at high speed and streams the data to the Cloud in real-time. Using unique, proprietary deep neural-network architectures, Presenso's analytic engine autonomously interlinks events with components within the machines and ultimately predicts evolving failures. In addition, it provides valuable information about the remaining time to failure and its origin within the machine [61].

According to a study of PWC, $67 \%$ of business leaders believe that AI and automation will impact negatively on stakeholder trust levels in their industry in the next five years. The central challenge is that many of the AI applications operate within black boxes, offering little if any discernible insight into how they reach their outcomes. The greater the confidence in AI, the faster and more widely can it be deployed [62].

SkyPlanner APS is an advanced planning and scheduling system using AI. The software includes AI that instantly optimizes work order, in which production is most efficiently scheduled. The AI algorithm also takes into account details that can further enhance production efficiency. For example, in many productions, it is advisable to schedule jobs that use the same materials or tools in succession [63]. $\mathrm{AI}$ is also able to more accurately estimate the time it takes to complete the different jobs.

Swarm Logistics is a deep-tech software technology company specializing in the development of intelligent, autonomous transportation systems. The Auto-Dispatcher of Swarm Logistics is based on a complex algorithm that is constantly improving itself with the use of artificial intelligence. This software was tested in a case study and compared to previous planning. The results of the comparison showed cost savings of $25 \%$ and $35 \%$ faster delivery for the transportation company [64].

Siemens Mobility is testing its ITS Digital Lab applications and services for smarter management of road traffic, fleets such as e-bikes, and intermodal mobility. Connected vehicles sending data in real-time, infrastructure systems transmitting their status to Siemens' internet-of-things platform MindSphere and road users who are connected with their smartphones all produce an immense amount of data. This rich and growing source of data is changing the types of services of mobility that are feasible. Siemens Mobility is working on solutions for a Balanced Intermodal Mobility Ecosystem, which manages not only the road network but also specific fleets within the network and ultimately the traveler across different modes of transportation [65].

\section{Discussion}

In this paper, the authors identified the following five clusters for the application of $\mathrm{AI}, \mathrm{ML}$, and DL in Smart Logistics: (1) frameworks for cyber-physical systems (CPS) in logistics; (2) AI, ML, and DL in the context of (predictive) maintenance; (3) decision support systems and man-machine interaction; (4) production planning and control systems, and (5) improvement of operational processes in logistics. In the above-described conceptual framework, we analyzed the main clusters where AI, ML, or DL are applied today or where the potential for application is already studied.

Looking at the first cluster in the proposed framework, AI and related technologies and methods will be used in the near future to do better forecasting and to better understand users and customers. This will have a significant impact on the optimization of the forecast on a strategic/tactical level and may be also used to determine new customer demand. In the future, AI may be used also in 
higher-level processes to detect fraud, prevent cybersecurity threats, and generally optimize higher-level processes. Possibilities of the future use of AI can also be in project management tasks, reducing the failure rate of projects thanks to predictive analysis and to more accurate project management. In addition, if AI algorithms can win chess games, they will also be able to be used in the generation of corporate strategies.

Taking a more detailed look at the second identified cluster dealing with the application of AI methods to create CPS in logistics, we can observe that already there are many research activities for realizing CPS and mono-directional information flow from the physical object to the digital model (digital shadow), and in a further step a bidirectional information flow between both models to control the physical system through a so-called digital twin [66]. CPS are receiving large amounts of different datasets and data from the logistics systems. Today, most of the practitioners face the challenge that they do not have the right tools to exploit the amount of data in the right manner. Here AI methods can complete the vision of a digital-twin-based control of logistics systems by analyzing big data from CPS, determining data patterns and therefore automating workflows and processes for more immediate and more qualitative control of logistics systems. Although some works deal with this topic, we find that, especially for logistics systems, this field is still an emerging research field with much need for further investigation and case study applications.

The third cluster deals with AI methods for realizing what we call predictive maintenance as an enhancement of preventive maintenance, which is well-known from lean management. Predictive maintenance as a concept has been well-discussed since the beginning of the new century, but looking at the Scopus database using this keyword, research on this concept has "exploded" in the years after 2017 when progress was made in the application of AI-based methods for realizing predictive maintenance. As AI methods depend a lot on the availability of a large amount of data, the field of predictive maintenance is a highly important research direction due to new generations of logistics systems equipped with sensors and providing large amounts of data that can be used for data analytics. Seeing this development, we consider predictive maintenance as one of the more consolidated fields of research for AI in logistics, although we are conscious of the fact that there is still a huge need for investigation especially for applied research and case study research.

The fourth cluster of "hybrid decision support systems" follows the current trend of human-centered engineering. Despite all of the potential for automation and digitalization in production and logistics, we have understood that many processes still depend from skilled workers and that the human will also in the future play a big and important role in the industry. What we can do is to support workers with cognitive assistance systems to enhance their capabilities in decision-making as well as taking advantage of a large amount of data. AI-based methods play a big role in this ongoing development of such digital aid systems for our workers. As indicated also in the analyzed literature, it will be important for the future not to only offer pure rational decision-making assistance tools, as this would decrease the role of the human from an intelligent individuum to a "stupid" executor of commands and decisions taken from a "super-intelligent system". It will become important to develop solutions using an approach based on so-called Explainable AI [67] and thus a hybrid way where the human is still able to understand the result through explainable interfaces. We state the hypothesis that only such hybrid systems will succeed in being applied also in practice, as the human being is still a skeptical individuum that would not accept assistance systems based on pure rational decision-making. While the use of AI in man-machine interactions has already been studied for many years, we consider therefore the development of decision-making systems based on explainable AI as one of the main future challenges in research.

The fifth cluster of "production planning and control systems" can be considered again as one of the already more developed and perhaps more consolidated fields compared to the other clusters identified in the proposed conceptual framework. For many years now production planning and control deal with the optimization of the planning when it comes to conduct advanced planning and scheduling tasks and to transfer this results in meaningful control mechanisms for production control. 
We can already find several works dealing with the use of simulation-based methods for scheduling since the early 1990s [68]. On the other hand, we postulate that there will be a "renaissance" in this field due to the ongoing trend of AI, opening an emerging field towards real-time planning. A human planner would never be able to process information as fast as AI does based on sensors and seamless vertical data integration. Through the combination of a steady increase of computational power and storage capacity for a large amount of data with sensor devices for collecting real-time data, real-time planning comes within reach in the near future.

The sixth cluster deals with improvements of operational processes in logistics that can often be deduced from nature, as the examples in the framework description have shown (see also [50-53]). The topic of biological transformation is an already emerging theme promoted, e.g., by the Fraunhofer research institutes [69] and other researchers [70], and describes the change from solely bioinspired manufacturing or logistics systems towards those that are bio-integrated and bio-intelligent by combining what we can deduce and learn from the observation of processes in nature and leaping computational power as well as progress in AI, ML, and DL.

The seventh cluster of "intelligent transport logistics" has been making enormous progress in data-based traffic optimization and the development of autonomous vehicles for years. With the latest technologies in object recognition, roads and important traffic junctions can be monitored even better in real-time, reducing possible delays in processing time. A great challenge for the future will be the investigation and finding of appropriate solutions for reducing or eliminating the risk of cyber-attacks and biased decisions about transport as well as discussing ethical questions regarding liability for the decisions taken by artificial intelligence in the place of humans. In this regard, for example, the EU is taking important steps to adapt its regulatory framework to these developments so that it supports innovation while at the same time ensuring respect for fundamental values and rights [71].

The following Table 8 summarizes the main research actions that can be deduced from the discussion of the identified clusters for applying AI, ML, and DL in Smart Logistics. In addition, it addresses also the experts/stakeholders that should be involved in research activities, as logistics is a broad field in which several different subjects, perspectives, and types of expertise converge. This should guarantee that further research is target-oriented and follows the needs of practitioners in the field of logistics. The listed research actions should motivate researchers of basic and applied research to conduct further research to exploit the full potential of $\mathrm{AI}, \mathrm{ML}$, and DL in the field of logistics.

Table 8. Research actions and experts/stakeholders to be involved.

\begin{tabular}{|c|c|c|c|}
\hline No. & Research Action & Cluster & Experts/Stakeholder \\
\hline 1 & $\begin{array}{l}\text { Further research on the automated } \\
\text { generation of corporate strategies }\end{array}$ & $\begin{array}{l}\mathrm{C} 1 \text {-Strategic and Tactical Process } \\
\text { Optimization }\end{array}$ & Top management \\
\hline 2 & $\begin{array}{l}\text { Further research for AI support in project } \\
\text { management to reduce failures and increase } \\
\text { the success of projects }\end{array}$ & $\begin{array}{l}\text { C1-Strategic and Tactical Process } \\
\text { Optimization }\end{array}$ & Project managers \\
\hline 3 & $\begin{array}{l}\text { Case study research on applications for } \\
\text { AI-based CPS in logistics }\end{array}$ & $\begin{array}{l}\text { C2-Cyber-Physical Systems in } \\
\text { Logistics }\end{array}$ & $\begin{array}{l}\text { Users and experts from all fields of } \\
\text { logistics }\end{array}$ \\
\hline 4 & $\begin{array}{l}\text { Case study research on applications of } \\
\text { predictive maintenance }\end{array}$ & C3-Predictive Maintenance & $\begin{array}{l}\text { Maintenance managers of logistics } \\
\text { systems and vehicle fleets }\end{array}$ \\
\hline 5 & $\begin{array}{l}\text { Further research on explainable AI for } \\
\text { AI-based hybrid decision support systems }\end{array}$ & $\begin{array}{l}\text { C4-Hybrid Decision Support } \\
\text { Systems }\end{array}$ & $\begin{array}{l}\text { Users and experts from all fields of } \\
\text { logistics }\end{array}$ \\
\hline 6 & Real-time planning and (re-)scheduling & $\begin{array}{l}\text { C5-Production Planning and } \\
\text { Control Systems }\end{array}$ & $\begin{array}{l}\text { Production planners and } \\
\text { intralogistics experts }\end{array}$ \\
\hline 7 & $\begin{array}{l}\text { Learning from nature through } \\
\text { bio-intelligence in logistics }\end{array}$ & $\begin{array}{l}\text { C6-Improvement of Operational } \\
\text { Processes in Logistic }\end{array}$ & Operations managers \\
\hline 8 & $\begin{array}{l}\text { Development of low-cost real-time } \\
\text { monitoring devices/solutions }\end{array}$ & $\begin{array}{l}\text { C7-Intelligent Transport } \\
\text { Logistics }\end{array}$ & Traffic Planners, hardware providers \\
\hline 9 & $\begin{array}{l}\text { Clarify questions and provide solutions for } \\
\text { reducing the risk of cyber-attacks and } \\
\text { regarding ethical/liability questions }\end{array}$ & $\begin{array}{l}\text { C7-Intelligent Transport } \\
\text { Logistics }\end{array}$ & Experts in ethics and cybersecurity \\
\hline
\end{tabular}




\section{Limitations and Implications}

\subsection{Limitations of This Study}

The study conducted a review of the scientific literature from 2014 to January 2019, the date of data extraction from the Scopus scientific database. A limit of this research is that during the period of the screening, selection and analysis and development of the framework, further research on AI in logistics may have been performed and published. We are aware that the current rapid development of research in this area is a limit for the results of this review. For this reason, in the following we have summarized the most important work that has been done on this topic in the period from the beginning of 2019 to the beginning of 2020, to analyze whether further research directions have emerged. Firstly, this analysis confirmed the proposed framework, as also after the period investigated by the authors, many works deal with the clusters identified. In addition, a scientific discussion on some new topics has been started. The following short overview does not present an exhaustive list of new research topics, but some examples of the most interesting ones.

Giusti et al. address synchromodal logistics as an emergent topic in logistics and transportation where AI-based methods may open new possibilities. Synchromodality is an emerging and attractive concept in logistics, developed and established in the Benelux region during the last decade. The main purpose of synchromodality is reducing costs, emissions, and delivery times while maintaining the quality of supply chain service through the smart utilization of available resources and synchronization of transport flows [72].

In Le et al. neural network-based approaches are used for example to estimate, predict, and optimize fuel consumption for container ships in Korea. The developed model has thus been applied to confirm the effectiveness of the slow-steaming method for achieving energy efficiency [73].

Liu et al. examine the effects of context-awareness on the ambient intelligence of logistics service quality, as context-awareness makes it possible to provide personalized service for each client. Context-awareness-based ambient intelligence predicts users' intention-to-use depending on the contexts they provide. By applying the prediction to logistics services, it can provide customized service to keep clients satisfied. A key issue in user-centered services is how to detect each user-specific situation and choose a certain service that meets users' requirements the best, and then to provide support for real-time decision-making [74].

According to Ceyhun, using AI will contribute to the prevention of ship-related accidents by anticipating future cases by using pinpoint calculations [75].

Another use of AI-based methods will be to develop intelligent road inspection systems for smart mobility and transportation maintenance systems [76].

\subsection{Implications for Academia and Practitioners}

From our point of view, this research is interesting for both academics and practitioners. While there are now some literature review articles on artificial intelligence, machine learning, or deep learning in manufacturing or business processes, there is a great lack of such review articles in the field of logistics. With this paper, researchers can find a comprehensive review of the current state of research. In addition, the paper presents a framework for the use of AI, ML, or DL in logistics. This framework, as well as the research actions and fields collected in the discussion Section, should contribute to and encourage researchers to carry out further research in these areas and thus take an important step towards consolidating these areas.

More and more managers and practitioners from logistics companies or logistics sectors are interested in the potential of AI-based methods in logistics. However, the complexity of these topics makes it very difficult for practitioners to estimate their use or even to get an overview of the current status. Therefore, it was our concern after the creation of the framework, which is informative for academics as well as for practitioners, to show practical examples from management literature and 
case studies. This will provide practitioners with an overview of the current methods as well as new input to plan and start initiatives for the use of $\mathrm{AI}$ in their logistics processes.

\section{Conclusions}

In the context of Smart Logistics, the application of AI, ML, and DL technologies is still in an early stage of development. Most of the identified studies are concepts, laboratory experiments, or in a very early testing phase. Mature industrial applications are still missing. However, the continuous reporting of machine settings, machine states, quality parameter settings, predictive maintenance, decision-making support systems, advanced scheduling, planning, and control approaches in the research fields of inventory management, flow shop problems, traditional job shop scheduling problems, production process optimization, and the improvement of operational logistics processes, e.g., identification and tracking approaches, can be seen as promising areas within the Smart Logistics framework.

The findings of this research study should be used as a starting point for future investigations regarding the application of $\mathrm{AI}, \mathrm{ML}$, and DL technologies in the area of Smart Logistics in industrial enterprises, and provide a framework for practitioners in industrial companies for the successful implementation of state-of-the-art technologies as well. Therefore, it is important to integrate different research areas, e.g., information technology, logistics, mechanical engineering, industrial engineering, mathematics, and statistics, into future research projects.

Author Contributions: H.Z. led and supervised the research project. M.W. and E.R. organized, planned, and conducted the SLR. All authors have read and agreed to the published version of the manuscript.

Funding: This research was funded by the project "SME 4.0-Industry 4.0 for SMEs" (funded by the European Union's Horizon 2020 R\&I program under the Marie Skłodowska-Curie grant agreement No. 734713).

Conflicts of Interest: The authors declare no conflict of interest.

\section{References}

1. Matt, D.T.; Modrák, V.; Zsifkovits, H. Industry 4.0 for SMEs; Springer: Berlin/Heidelberg, Germany, 2020.

2. Zsifkovits, H.; Woschank, M. Smart Logistics-Technologiekonzepte und Potentiale. BHM Berg Hüttenmännische Monatshefte 2019, 164, 42-45. [CrossRef]

3. Bosch, G.; Bromberg, T.; Haipeter, T.; Schmitz, J. Industrie und Arbeit 4.0: Befunde zu Digitalisierung und Mitbestimmung im Industriesektor auf Grundlage des Projekts "Arbeit 2020". In IAQ-Report: Akutelle Forschungsergebnisse aus dem Institut Arbeit und Qualifikation; IAQ: Duisburg Essen, Germany, 2017. Available online: http://www.iaq.uni-due.de/iaq-report/2017/report2017-04.pdf (accessed on 1 March 2020).

4. Kagermann, H.; Anderl, R.; Gausemeier, J.; Schuh, G.; Wahlster, W. Industrie 4.0 in a Global Context: Strategies for Cooperating with International Partners; Herbert Utz Verlag: Munich, Germany, 2016.

5. Dallasega, P.; Woschank, M.; Ramingwong, S.; Tippayawong, K.; Chonsawat, N. Field study to identify requirements for smart logistics of European, US and Asian SMEs. In Proceedings of the International Conference on Industrial Engineering and Operations Management, Bangkok, Thailand, 5-7 March 2019; pp. 844-855.

6. Dallasega, P.; Woschank, M.; Zsifkovits, H.; Tippayawong, K.; Brown, C.A. Requirement Analysis for the Design of Smart Logistics in SMEs. In Industry 4.0 for SMEs; Matt, D.T., Modrák, V., Zsifkovits, H., Eds.; Springer: Berlin/Heidelberg, Germany, 2020; pp. 147-162.

7. Cioffi, R.; Travaglioni, M.; Piscitelli, G.; Petrillo, A.; de Felice, F. Artificial Intelligence and Machine Learning Applications in Smart Production: Progress, Trends, and Directions. Sustainability 2020, 12, 1-24. [CrossRef]

8. Mc Carthy, J.; Minsky, M.L.; Rochester, N.; Shannon, C.E. A Proposal for the Dartmouth Summer Research Project on Artificial Intelligence. AI Mag. 2006, 27, 12-14.

9. Shalev-Shwartz, S.; Ben-David, S. Understanding Machine Learning: From Theory to Algorithms; Cambridge University Press: Cambridge, UK, 2014.

10. Diez-Olivan, A.; Del Ser, J.; Galar, D.; Sierra, B. Data Fusion and Machine Learning for Industrial Prognosis: Trends and Perspectives towards Industry 4.0. Inf. Fusion 2019, 50, 92-111. [CrossRef] 
11. Dey, N.; Ashour, A.S.; Nguyen, G.N. Deep Learning for Multimedia Content Analysis. In Mining Multimedia Documents; Karaa, W.B.A., Dey, N., Eds.; CRC Press: Boca Raton, FL, USA, 2017; pp. 193-203.

12. Salehi, H.; Burgueño, R. Emerging artificial intelligence methods in structural engineering. Eng. Struct. 2018, 171, 170-189. [CrossRef]

13. Hamet, P.; Tremblay, J. Artificial intelligence in medicine. Metab. Clin. Exp. 2017, 69S, 36-40. [CrossRef]

14. Baryannis, G.; Validi, S.; Dani, S.; Antoniou, G. Supply chain risk management and artificial intelligence: State of the art and future research directions. Int. J. Prod. Res. 2018, 57, 2179-2202. [CrossRef]

15. Wirth, N. Hello marketing, what can artificial intelligence help you with? Int. J. Mark. Res. 2018, 60, 435-438. [CrossRef]

16. Hokka, M.; Kaakinen, P.; Polkki, T. A systematic review: Non-pharmacological interventions in treating pain in patients with advanced cancer. J. Adv. Nurs. 2014, 70, 1954-1969. [CrossRef]

17. Töpfer, A. Erfolgreich Forschen: Ein Leitfaden für Bachelor-, Master-Studierende und Doktoranden, 3rd ed.; Springer: Berlin/Heidelberg, Germany, 2012.

18. Booth, A.; Sutton, A.; Papaioannou, D. Systematic Approaches to a Successful Literature Review, 2nd ed.; SAGE: London, UK, 2016.

19. Ali, N.B.; Usman, M. Reliability of search in systematic reviews: Towards a quality assessment framework for the automated-search strategy. Inf. Softw. Technol. 2018, 99, 133-147. [CrossRef]

20. Palmarini, R.; Erkoyuncu, J.A.; Roy, R.; Torabmostaedi, H. A systematic review of augmented reality applications in maintenance. Robot. Comput. Manuf. 2018, 49, 215-228. [CrossRef]

21. Tranfield, D.; Denyer, D.; Smart, P. Towards a Methodology for Developing Evidence-Informed Management Knowledge by Means of Systematic Review. Br. J. Manag. 2003, 14, 207-222. [CrossRef]

22. Petticrew, M.; Roberts, H. Systematic Reviews in the Social Sciences: A Practical Guide; Blackwell Publisher: Malden, MA, USA, 2012.

23. Denyer, D.; Tranfield, D. Producing a systematic review. In The Sage Handbook of Organizational Research Methods; Buchanan, D.A., Bryman, A., Eds.; Sage Publications Inc.: Thousand Oaks, CA, USA, 2011; pp. 671-689.

24. Durach, C.F.; Kembro, J.; Wieland, A. A New Paradigm for Systematic Literature Reviews in Supply Chain Management. J. Supply Chain Manag. 2017, 53, 67-85. [CrossRef]

25. Gursch, H.; Wuttei, A.; Gangloff, T. Learning Systems for Manufacturing Management Support. 2016. Available online: http://ceur-ws.org/Vol-1793/paper5.pdf (accessed on 1 March 2020).

26. Brodsky, A.; Krishnamoorthy, M.; Menasce, D.A.; Shao, G.; Rachuri, S. Toward smart manufacturing using decision analytics. In Proceedings of the 2014 IEEE International Conference on Big Data (Big Data), Washington, DC, USA, 27-30 October 2014; pp. 967-977.

27. Qu, S.; Jian, R.; Chu, T.; Wang, J.; Tan, T. Computational reasoning and learning for smart manufacturing under realistic conditions. In Proceedings of the 2014 International Conference on Behavior, Economic and Social Computing (BESC), Shanghai, China, 30 October-2 November 2014; pp. 1-8.

28. Bonino, D.; Vergori, P. Agent Marketplaces and Deep Learning in Enterprises: The COMPOSITION Project. In Proceedings of the 2017 IEEE 41st Annual Computer Software and Applications Conference (COMPSAC), Turin, Italy, 4-8 July 2017; pp. 749-754.

29. Peres, R.S.; Dionisio Rocha, A.; Leitao, P.; Barata, J. IDARTS-Towards intelligent data analysis and real-time supervision for industry 4.0. Comput. Ind. 2018, 101, 138-146. [CrossRef]

30. Guo, Q.; Miyamae, Y.; Wang, Z.; Taniuchi, K.; Yang, H.; Liu, Y. Senvis-Net: Learning from Imbalanced Machinery Data by Transferring Visual Element Detectors. Int. J. Mach. Learn. Comput. 2018, 8, 416-422.

31. Ferrer, B.R.; Mohammed, W.M.; Martinez Lastra, J.L.; Villalonga, A.; Beruvides, G.; Castano, F.; Haber, R.E. Towards the Adoption of Cyber-Physical Systems of Systems Paradigm in Smart Manufacturing Environments. In Proceedings of the 2018 IEEE 16th International Conference on Industrial Informatics (INDIN), Porto, Portugal, 18-20 July 2018; pp. 792-799.

32. Thalmann, S.; Mangler, J.; Schreck, T.; Huemer, C.; Streit, M.; Pauker, F.; Weichhart, G.; Schulte, S.; Kittl, C.; Pollak, C.; et al. Data Analytics for Industrial Process Improvement A Vision Paper. In Proceedings of the 2018 IEEE 20th Conference on Business Informatics (CBI), Vienna, Austria, 11-13 July 2018; pp. 92-96.

33. Morozov, D.; Lezoche, M.; Panetto, H. Multi-paradigm modelling of Cyber-Physical Systems. IFAC-PapersOnLine 2018, 51, 1385-1390. [CrossRef] 
34. Marrella, A.; Mecella, M. Cognitive Business Process Management for Adaptive Cyber-Physical Processes. In Business Process Management Workshops; Teniente, E., Weidlich, M., Eds.; Springer: Berlin/Heidelberg, Germany, 2018; pp. 429-439.

35. Marrella, A.; Mecella, M.; Sardiña, S. Supporting adaptiveness of cyber-physical processes through action-based formalisms. AI Commun. 2018, 31, 47-74. [CrossRef]

36. Subakti, H.; Jiang, J.-R. Indoor Augmented Reality Using Deep Learning for Industry 4.0 Smart Factories. In Proceedings of the 2018 IEEE 42nd Annual Computer Software and Applications Conference (COMPSAC), Tokyo, Japan, 23-27 July 2018; pp. 63-68.

37. Susto, G.A.; Schirru, A.; Pampuri, S.; Beghi, A.; De Nicolao, G. A hidden-Gamma model-based filtering and prediction approach for monotonic health factors in manufacturing. Control. Eng. Pract. 2018, 74, 84-94. [CrossRef]

38. Wang, K.; Wang, Y. How AI Affects the Future Predictive Maintenance: A Primer of Deep Learning. In Advanced Manufacturing and Automation VII; Wang, K., Wang, Y., Strandhagen, J.O., Yu, T., Eds.; Springer: Berlin/Heidelberg, Germany, 2018; pp. 1-9.

39. Klein, P.; Bergmann, R. Data Generation with a Physical Model to Support Machine Learning Research for Predictive Maintenance. In Proceedings of the LWDA 2018, Mannheim, Germany, 22-24 August 2018; pp. 179-190.

40. Cho, S.; May, G.; Tourkogiorgis, I.; Perez, R.; Lazaro, O.; de La Maza, B.; Kiritsis, D. A Hybrid Machine Learning Approach for Predictive Maintenance in Smart Factories of the Future. In Advances in Production Management Systems. Smart Manufacturing for Industry 4.0; Moon, I., Lee, G.M., Park, J., Kiritsis, D., von Cieminski, G., Eds.; Springer: Berlin/Heidelberg, Germany, 2018; pp. 311-317.

41. Wuest, T.; Weimer, D.; Irgens, C.; Thoben, K.-D. Machine learning in manufacturing: Advantages, challenges, and applications. Prod. Manuf. Res. 2016, 4, 23-45. [CrossRef]

42. Terziyan, V.; Gryshko, S.; Golovianko, M. Patented intelligence: Cloning human decision models for Industry 4.0. J. Manuf. Syst. 2018, 48, 204-217. [CrossRef]

43. Venkatapathy, A.K.R.; Bayhan, H.; Zeidler, F.; Hompel, M. Human Machine Synergies in Intra-Logistics: Creating a Hybrid Network for Research and Technologies. In Proceedings of the 2017 Federated Conference on Computer Science and Information Systems, Prague, Czech Republic, 3-6 September 2017; pp. 1065-1068.

44. Zeidler, F.; Bayhan, H.; Ramachandran Venkatapathy, A.K.; ten Hompel, M. Referenzfeld zur Erforschung und Entwicklung neuartiger hybrider Formen der Zusammenarbeit von Menschen und Maschinen in der Logistik. Logist. J. Proc. 2017, 1, 1-8. Available online: https://www.logistics-journal.de/proceedings/2017/ 4593/zeidler_2017.pdf (accessed on 1 March 2020). [CrossRef]

45. Lolli, F.; Balugani, E.; Ishizaka, A.; Gamberini, R.; Rimini, B.; Regattieri, A. Machine learning for multi-criteria inventory classification applied to intermittent demand. Prod. Plan. Control. 2018, 30, 76-89. [CrossRef]

46. He, L.; Li, W.; Zhang, Y.; Cao, J. Review of Swarm Intelligence Algorithms for Multi-objective Flowshop Scheduling. In Internet and Distributed Computing Systems; Xiang, Y., Sun, J., Fortino, G., Guerrieri, A., Jung, J.J., Eds.; Springer: Berlin/Heidelberg, Germany, 2018; pp. 258-269.

47. Zhang, J.; Ding, G.; Zou, Y.; Qin, S.; Fu, J. Review of job shop scheduling research and its new perspectives under Industry 4.0. J. Intell. Manuf. 2017, 30, 1809-1830. [CrossRef]

48. Gomes, M.; Silva, F.; Ferraz, F.; Silva, A.; Analide, C.; Novais, P. Developing an Ambient Intelligent-Based Decision Support System for Production and Control Planning. In Intelligent Systems Design and Applications; Madureira, A.M., Abraham, A., Gamboa, D., Novais, P., Eds.; Springer: Berlin/Heidelberg, Germany, 2017; pp. 984-994.

49. Luetkehoff, B.; Blum, M.; Schroeter, M. Self-learning Production Control Using Algorithms of Artificial Intelligence. In Collaboration in a Data-Rich World; Camarinha-Matos, L.M., Afsarmanesh, H., Fornasiero, R., Eds.; Springer: Berlin/Heidelberg, Germany, 2017; pp. 299-306.

50. Wen, J.; He, L.; Zhu, F. Swarm Robotics Control and Communications: Imminent Challenges for Next Generation Smart Logistics. IEEE Commun. Mag. 2018, 56, 102-107. [CrossRef]

51. Laux, H.; Bytyn, A.; Ascheid, G.; Schmeink, A.; Kurt, G.K.; Dartmann, G. Learning-based indoor localization for industrial applications. In Proceedings of the 15th ACM International Conference, New York, NY, USA, 24-29 September 2018; pp. 355-362. 
52. Ademujimi, T.T.; Brundage, M.P.; Prabhu, V.V. A Review of Current Machine Learning Techniques Used in Manufacturing Diagnosis. In Advances in Production Management Systems. The Path to Intelligent, Collaborative and Sustainable Manufacturing; Lödding, H., Riedel, R., Thoben, K.-D., von Cieminski, G., Kiritsis, D., Eds.; Springer: Berlin/Heidelberg, Germany, 2017; pp. 407-415.

53. Teschemacher, U.; Reinhart, G. Ant Colony Optimization Algorithms to Enable Dynamic Milkrun Logistics. Procedia CIRP 2017, 63, 762-767. [CrossRef]

54. Li, D.; Deng, L.; Cai, Z.; Franks, B.; Yao, X. Intelligent Transportation System in Macao Based on Deep Self-Coding Learning. IEEE Trans. Ind. Inform. 2018, 14, 3253-3260. [CrossRef]

55. Cheng, J.; Wu, W.; Cao, J.; Li, K. Fuzzy group-based intersection control via vehicular networks for smart transportations. IEEE Trans. Ind. Inform. 2017, 13, 751-758. [CrossRef]

56. Li, B.Y.S.; Yeung, L.F.; Tsang, K.F. Analysing traffic condition based on IoT technique. In Proceedings of the 2014 IEEE International Conference on Consumer Electronics (ICCE-C 2015), Shenzhen, China, 10-13 January 2015; pp. 1-4.

57. Edelstein, R. Smarter transportation management through its. In Proceedings of the 21st World Congress on Intelligent Transport Systems, ITSWC 2014: Reinventing Transportation in Our Connected World, Detroit, MI, USA, 7-11 September 2014; pp. 1-4.

58. Woschank, M. The Impact of Decision Making Maturity on Decision Making Efficiency. Ph.D. Thesis, University of Latvia, Riga, Latvia, 2018.

59. Aitheon. Project Management. Available online: https://aitheon.com/project-management (accessed on 19 April 2020).

60. DHL Research. Digital Twins in Logistics. A DHL Perspective on the Impact of Digital Twins on the Logistics Industry. Available online: https://www.dhl.com/content/dam/dhl/global/core/documents/pdf/glo-coredigital-twins-in-logistics.pdf (accessed on 19 April 2020).

61. Presenso. Presenso Announces the Production Release of Its Predictive Maintenance Solution. Available online: https://www.prnewswire.com/news-releases/presenso-announces-the-production-release-of-itspredictive-maintenance-solution-839580485.html (accessed on 19 April 2020).

62. PWC. Explainable AI Driving Business Value through Greater Understanding. Electronically. Available online: https://www.pwc.co.uk/audit-assurance/assets/explainable-ai.pdf (accessed on 19 April 2020).

63. Skycode. SkyPlanner APS-AI Production Planning and Scheduling. Available online: https://skycode.fi/en/ skyplanner-aps-ai-production-planning-and-scheduling/ (accessed on 19 April 2020).

64. Swarm Logistics. Available online: https://www.swarmlogistics.net/proof-of-concept-validates-swarmlogistics-system.html (accessed on 19 April 2020).

65. Siemens Mobility. AI-Based Traffic and City Mobility Solutions. Available online: https://www.mobility. siemens.com/global/en/portfolio/road/digital-lab.html (accessed on 29 April 2020).

66. Kritzinger, W.; Karner, M.; Traar, G.; Henjes, J.; Sihn, W. Digital Twin in manufacturing: A categorical literature review and classification. IFAC-PapersOnLine 2018, 51, 1016-1022. [CrossRef]

67. Rai, A. Explainable AI: From black box to glass box. J. Acad. Mark. Sci. 2019, 48, 137-141. [CrossRef]

68. Aytug, H.; Bhattacharyya, S.; Koehler, G.; Snowdon, J. A review of machine learning in scheduling. IEEE Trans. Eng. Manag. 1994, 41, 165-171. [CrossRef]

69. Miehe, R.; Bauernhansl, T.; Schwarz, O.; Traube, A.; Lorenzoni, A.; Waltersmann, L.; Full, J.; Horbelt, J.; Sauer, A. The biological transformation of the manufacturing industry-envisioning biointelligent value adding. Procedia CIRP 2018, 72, 739-743. [CrossRef]

70. Matt, D.T.; Riedl, M.; Rauch, E. Die Natur als Inspiration. ZWF Zeitschrift Wirtschaftlichen Fabrikbetrieb 2020, 115, 158-161. [CrossRef]

71. European Parliament. Artificial Intelligence in Transport. Available online: https://www.europarl.europa.eu/ RegData/etudes/BRIE/2019/635609/EPRS_BRI(2019)635609_EN.pdf (accessed on 29 April 2020).

72. Giusti, R.; Manerba, D.; Bruno, G.; Tadei, R. Synchromodal logistics: An overview of critical success factors, enabling technologies, and open research issues. Transp. Res. Part. E Logist. Transp. Rev. 2019, 129, 92-110. [CrossRef]

73. Le, L.T.; Lee, G.; Park, K.S.; Kim, H. Neural network-based fuel consumption estimation for container ships in Korea. Marit. Policy Manag. 2020, 1, 1-18. [CrossRef] 
74. Liu, C.; Park, E.; Jiang, F. Examining effects of context-awareness on ambient intelligence of logistics service quality: User awareness compatibility as a moderator. J. Ambient. Intell. Humaniz. Comput. 2018, 11, 1413-1420. [CrossRef]

75. Ceyhun, G.Ç. Recent Developments of Artificial Intelligence in Business Logistics: A Maritime Industry Case. In Digital Business Strategies in Blockchain Ecosystems; Springer: Berlin/Heidelberg, Germany, 2020; pp. 343-353.

76. Karballaeezadeh, N.; Zaremotekhases, F.; Shamshirband, S.; Mosavi, A.; Nabipour, N.; Csiba, P.; Várkonyi-Kóczy, A.R. Intelligent Road Inspection with Advanced Machine Learning; Hybrid Prediction Models for Smart Mobility and Transportation Maintenance Systems. Energies 2020, 13, 1718-1741. [CrossRef]

(C) 2020 by the authors. Licensee MDPI, Basel, Switzerland. This article is an open access article distributed under the terms and conditions of the Creative Commons Attribution (CC BY) license (http://creativecommons.org/licenses/by/4.0/). 